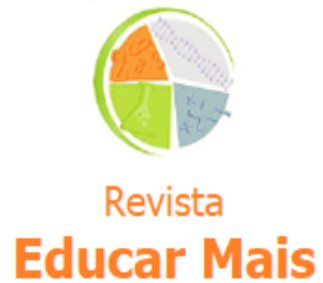

EDITORIAL

\title{
A educação científica do campo
}

\author{
Profa Dra. Josiane de Souza ${ }^{1}$
}

Desde 2010, quando foi lançado o primeiro edital do Procampo pelo MEC, mais de 30 instituições de ensino superior aderiram ao programa propondo Licenciaturas em Educação do Campo com habilitações relacionadas às ciências da natureza. Essas novas propostas explicitaram a urgência do diálogo entre as áreas de educação do campo e educação em ciências, que, até então, ocorria de forma muito tímida. Para pensar esse diálogo, no entanto, é imprescindível que se considere a diferença histórica, cultural e social da construção destas áreas no Brasil, pois não há formas de propor um discurso dialógico sem que se conheça as construções discursivas que se propõem a dialogar. Para Bakhtin (2009, 2011, 2015), os enunciados, que compõem os discursos, são constituídos por diversas vozes, contemporâneas ou do passado e, portanto, conceber os contextos extraverbais de construção discursiva das áreas é um caminho salutar e possível para que a aproximação seja efetiva.

Em uma pesquisa bibliográfica, recentemente realizada (SOUZA, 2020), pôde-se notar que as trajetórias históricas dessas áreas são diferentes e que as vozes com que cada área tem dialogado ao longo dos anos, em vários momentos, não se assemelham. Já no início do século XX as diferenças se mostravam visíveis, pois enquanto os povos do campo viam crescer o seu desprestígio social com a industrialização impulsionada pela crise de 1929 (VENDRAMINI, 2013), a educação em ciências buscava formar, com princípios de neutralidade e imparcialidade científica, apenas uma pequena parte da população que integraria a elite. Esse diálogo com a elite rendeu à área de educação em ciências prestígio e privilégios em políticas públicas, como ocorreu na Lei de Diretrizes e Bases de 1971, que ampliava a participação das ciências no currículo, ratificando sua importância social, econômica e cultural, ainda que as disciplinas científicas fossem ministradas de forma neutra e racionalista, dissociadas de outras esferas sociais (KRASILCHIK, 2000).

As diferenças históricas entre as áreas se acentuaram durante o período de Ditadura Militar, pois havia nesse momento um modelo educacional urbano que foi privilegiado por representar tudo que os governantes da época acreditavam. Dessa forma, o discurso da educação em ciências foi adequado para privilegiar a neutralidade e a objetividade da ciência e dialogar com vozes internacionais, ignorando carências e dificuldades nacionais. Esse fato levou à caracterização da educação em ciências no currículo a partir da perspectiva da ciência aplicada e à valorização da educação profissionalizante. Por outro lado, a educação rural foi sucateada e submetida a perspectivas que

\footnotetext{
${ }^{1}$ Licenciada em Física, Mestra e Doutora em Ensino de Física e Docente do Instituto Federal Sul-rio-grandense (IFSUL), Santana do Livramento/RS - Brasil. E-mail: josianesouza@ifsul.edu.br
} 
subordinavam o campo à cidade e fomentavam o agronegócio em detrimento da agricultura familiar (FERNANDES, 1999).

Nos anos 1990, com a aprovação da Lei de Diretrizes e Bases de 1996, o discurso vinculado à educação passa a ser mais progressista, aliando a formação do estudante à tríade cidadãotrabalhador-estudante. Uma voz que aparece nessa política, ainda que de forma tímida, é a da formação crítica, prevendo que os estudantes sejam formados, para além do mercado de trabalho, mas de forma a serem críticos e participativos na sociedade. A pesquisa em educação em ciências, também motivada por essas mudanças políticas na concepção educacional brasileira, começa a buscar referenciais menos alinhados ao racionalismo técnico, dando início a temas de pesquisa como o da alfabetização científica e da perspectiva curricular alinhada ao Movimento CTS. Porém, ainda que essa Lei tenha sido promissora para a educação em ciências e que considerasse o respeito às particularidades rurais em sua estrutura, ela falhou ao não definir a educação rural, dando margem a diferentes interpretações e práticas. Nessas diferentes concepções, a que subordina o campo à cidade e que incute a noção de que a educação rural deve ser igual à urbana é a voz que mais repercutiu, levando a educação no meio rural ao declínio.

Porém, foi também nos anos 90 que os povos do campo se uniram e fizeram se ouvir na luta pela libertação e valorização do meio rural. Nesse momento, o conceito educação do campo é concebido e colocado como discurso oposto à educação rural. Esse conceito é carregado de significados ideológicos, que concebem uma educação em diálogo com as necessidades dos povos do campo, na luta por dignidade e justiça social. Assim, a educação do campo está comprometida, segundo Caldart (2012), não apenas com a luta pela educação, mas também com a luta pela terra, pela Reforma Agrária, pelo direito ao trabalho, à cultura, à soberania alimentar e ao território. Nos anos 2000, 0 Movimento por uma Educação do Campo ganha força e conquista o Pronacampo e o Procampo, levando a voz dos movimentos sociais para as políticas públicas e instituições de ensino superior. Nesse período, a pesquisa em educação em ciências no Brasil teve visível evolução tanto do ponto de vista teórico quanto metodológico. Entretanto, apesar da pesquisa ter evoluído, seus resultados não chegam na sala de aula, seja por falta de estrutura da escola, condições de trabalho do professor ou de sua formação (AULER, 2007), o que mantém a prática do ensino de ciências no Brasil e a pesquisa, dissociadas entre si.

Este quadro nos leva a entender que as esferas sociais em que os discursos da educação em ciências e da educação do campo estão inseridos são diferentes e que os contextos extraverbais de produção de cada discurso, apesar de localizados no mesmo tempo-espaço e influenciados pelo mesmo modelo político e econômico, também diferem entre si. Enquanto a história da educação em ciências tem sido marcada desde sua origem pela aproximação com as ciências da natureza, que sempre mantiveram prestígio no modelo capitalista de sociedade, a história da educação do campo se constituiu por um conjunto de movimentos sociais que impulsionaram políticas educacionais avessas a esse modelo econômico. Essa tensão deve ser levada em conta para a construção discursiva que busca aproximar as duas áreas.

Não devemos, no entanto, compreender esse resgate histórico como uma crítica ou julgamento de valores, mas, como necessário ao entendimento de práticas e metodologias que até hoje se fazem presentes na educação em ciências e na educação do campo brasileiros. Há de se compreender que as constituições históricas interferem na formação de profissionais e que, portanto, vários desafios devem surgir no diálogo entre essas áreas. A compreensão das vozes com que ambas áreas têm 
dialogado ao longo dos anos nos levou a entender que a hibridização de conhecimentos, no que chamamos de educação científica do campo, é um caminho promissor. Essa nova concepção, pautada na perspectiva crítica, propõe o processo formativo do docente de ciências, no contexto da educação do campo, como palco para a educação de conteúdos técnicos hibridizados com questões políticas, econômicas, sociais e culturais, preconizando a formação de cidadãos críticos capazes e interessados em atuar na sociedade.

A educação científica do campo engloba todas as esferas educativas que compõem a educação do campo. Porém, apresentamos um recorte para exemplificar como seria essa proposta vinculada à formação docente no contexto das Licenciaturas em Educação do Campo. Nossa proposta é pautada na perspectiva formativa baseada no docente intelectual crítico (CONTRERAS, 2012), na perspectiva curricular CTS/Freire e nas ideias de renovação da concepção da ciência, de Boaventura de Sousa Santos e Hugh Lacey.

O papel ativo do docente intelectual crítico se alinha com o que imaginamos para a formação do docente comprometido com a educação científica do campo, pois representa o docente que procura construir o seu discurso em sala de aula por meio das vozes de diversos atores sociais, promovendo a reflexão crítica. $O$ docente intelectual crítico é uma concepção que compreende o profissional como integrado à realidade e ativo em suas lutas e reinvindicações e que compreende, efetivamente, seu papel transformador da realidade. Entendemos que essa concepção docente é capaz de subverter o modelo educacional urbano, fomentado pelas políticas públicas e índices avaliativos educacionais, pois leva em conta toda a complexidade da dinâmica social campesina, as lutas sociais dos trabalhadores do campo e dialoga com os diversos atores envolvidos no processo pedagógico, cultural e político do campo. Para compor essa concepção de formação docente, buscamos uma concepção de currículo que correspondesse a estes objetivos.

A perspectiva híbrida que alia CTS às ideias de Paulo Freire pode contribuir para o desenvolvimento da educação científica do campo, já que relacionada questões da ciência com a realidade campesina brasileira. A abordagem CTS contribui com visões contra-hegemônicas acerca de ciência, da tecnologia e da sociedade, ao relacionar a esses conceitos valores ligados aos interesses coletivos, e questionar a ordem capitalista que impõe valores econômicos em detrimento dos demais valores (SANTOS e MORTIMER, 2002). A perspectiva Freireana, por sua vez, assume a concepção de educação problematizadora, dialógica em sua essência e que concebe os indivíduos enquanto seres históricos. Esses pressupostos permitem que, situações de opressão, antes vistas como irremediáveis e fatalistas, sejam compreendidas em sua origem, o que estimula a consciência crítica acerca da realidade. Logo, a estrutura curricular da educação científica do campo, inspirada nessa perspectiva, não será definida de antemão, mas deverá ser construída e organizada ao longo da prática com a participação dos estudantes, docentes e da comunidade onde os estudantes estão inseridos, visando à formação crítica. É importante que nesse processo, líderes, representantes dos movimentos sociais e quaisquer sujeitos que componham aquele ambiente participem dos momentos definidos como levantamento preliminar e diálogos descodificadores. Pois, dessa forma, a construção do conhecimento científico será hibridizada com as questões sociais, políticas, econômicas, ambientais e culturais que a comunidade julgar relevantes.

A proposta de Boaventura de Sousa Santos também nos pareceu pertinente, na composição da educação científica do campo, na medida em que realiza uma crítica à relação colonialista, imposta ao mundo pelos países do norte global. Nessa relação, os países do sul são submetidos a políticas e 
organizações sociais hegemônicas, que produzem o silenciamento de culturas. Santos $(2007,2009)$ propõem um processo emancipatório, por meio da conscientização histórica acerca das relações sociais e culturais atuais, do reconhecimento das diferenças, da tradução de saberes e do desvelamento de todas as faces da ciência. Para o autor, o mundo capitalista desacredita conhecimentos por meio de um conjunto de modos de produção, que desqualifica culturas diversas concebendo-as como alternativa descartável e invisível à realidade. Tais modos de produção, que produzem ausências, silenciam indivíduos e excluem povos inteiros do direito à educação são chamados pelo autor de monoculturas - do saber e do rigor, do tempo linear, da naturalização das diferenças, da escala dominante e do produtivismo capitalista (SANTOS, 2007). Para subverter esses processos, Santos (2007) propõe as ecologias - dos saberes, das temporalidades, do reconhecimento, da transescala, das produtividades -, que dão voz e espaço para vários tipos de conhecimentos serem aprendidos de forma hibridizada. Em nossa proposta, o currículo da educação científica do campo é construído a partir dessas ecologias, levando em consideração as especificidades locais, fomentando lutas, valorizando a cultura do povo em contexto e privilegiando a aplicação da ciência edificante na sociedade.

A perspectiva filosófica de Hugh Lacey desestrutura a visão elitista da ciência, ao mostrar que seu desenvolvimento é permeado por valores sociais e morais, além dos valores cognitivos, o que possibilita um maior diálogo entre os conhecimentos científicos e comuns. A partir dessa crítica, 0 autor prioriza a valorização, no processo educativo, dos conhecimentos e das demandas locais e, ao criticar a concepção de ciência moderna, promove o desenvolvimento autêntico (LACEY, 1998, 2000). Esse desenvolvimento não prioriza o progresso material ou o crescimento econômico, mas a reconquista, pelos povos desfavorecidos, da capacidade humana de agir e determinar as estruturas de suas vidas, integrada ao crescimento econômico. Tal concepção incorpora novos valores, reelabora o conceito de justiça social e incorpora a diversidade cultural como forma de emersão de diferentes concepções positivas do próprio desenvolvimento.

A educação científica do campo está comprometida com as ideias de Santos e de Lacey, ao valorizar as questões locais, criar um espaço de formação crítica e questionar as relações hegemônicas capitalistas. Os conceitos e referenciais teóricos que trouxemos não são os únicos que poderiam balizar a construção de um currículo para a educação científica do campo, mas acreditamos que esse conjunto possa configurar um ponto de partida para futuros estudos que busquem desenvolver a educação científica do campo.

Nossa proposta inicial não busca esgotar possibilidades de estudos no futuro, mas contribuir com uma base teórico-metodológica para que os estudos acerca da educação científica do campo possam proliferar em nossa área. Temos consciência, no entanto, que vários desafios institucionais e pedagógicos surgirão quando a proposta extrapolar o recorte da formação docente ou passar da teoria para a prática. Porém, esses são desafios que podem ser vencidos com estudos e pesquisas; os desafios que nos parecem mais graves e difíceis de contornar ficam evidentes nos discursos e atos do governo brasileiro dos últimos anos. Sabemos que a luta pela manutenção de direitos, afirmação e espaço é contínua, mas, quando há ataque aberto e direto, seja em pronunciamentos oficiais ou extraoficiais, essa luta deve ser intensificada e a educação em ciências, enquanto área que mantém alguns privilégios, deve buscar o diálogo e, solidariamente, se unir ao discurso em defesa da educação do campo no nosso país. Deixamos, por fim, o convite aos colegas da área para que continuem e ampliem os estudos sobre a educação científica do campo, fortificando o diálogo entre as áreas e a necessária resistência. 


\section{Referências Bibliográficas}

AULER, D. Articulação entre Pressupostos do Educador Paulo Freire e o Movimento CTS: Novos Caminhos para a Educação em Ciências, Contexto e Educação, ano 22, n. 77, p. 167- 188, Jan/Jun, 2007.

BAKHTIN, M. M. (VOLOSHÍNOV, V. N.) Marxismo e filosofia da linguagem, 13a Edição, São Paulo, Hucitec, 2009.

BAKHTIN, M. M. Estética da criação verbal, 6a Edição, São Paulo, Editora WMF Martins Fontes, 2011.

BAKHTIN, M. M. Teoria do romance I: A estilística, 1ª Edição, São Paulo, Editora 34, 2015.

BRASIL, Lei no 5692 de 11 de Agosto de 1971. Disponível em: http://www.planalto.gov.br/ccivil_03/leis/15692.htm, acessado em 20 de Setembro de 2020 às $00: 45 h$.

BRASIL, Lei 9394 de 20 de Dezembro de 1996 - Lei de Diretrizes e Bases. Disponível em http://www.planalto.gov.br/ccivil_03/leis/L9394.htm, acessado em 25 de Agosto de 2017 às 03:40h.

CALDART, R.S. Educação do Campo. In CALDART, R.S., PEREIRA, I.B., ALENTEJANO, P. e FRIGOTTO, G. Dicionário da Educação do Campo, Rio de Janeiro, São Paulo: Escola Politécnica de Saúde Joaquim Venâncio, Expressão Popular, 2012.

CONTRERAS, J. A autonomia do professor. 2a Edição, São Paulo: Cortez, 2012.

FERNANDES, B.M. A relação e interação cidade-campo. In ARROYO, M.G.; FERNANDES, B.M. Por uma educação básica do campo: A Educação Básica e o Movimento Social do Campo, Brasília, DF: Articulação Nacional Por uma Educação Básica do Campo, 1999.

FREIRE, P. Pedagogia do Oprimido. 4a Edição, Rio de Janeiro: Paz e Terra, 1977.

KRASILCHIK, M. Reformas e Realidade o caso do ensino das ciências. São Paulo em Perspectiva, V. 14, n. 1, p. 85-93, 2000.

LACEY, H. Valores e Atividade Científica.1ª Edição, São Paulo: Discurso Editorial, 1998.

LACEY, H. As formas nas quais as ciências são e não são livres de valores. Anais do $\mathbf{1 1}^{\circ}$ Congresso Internacional de Lógica, Metodologia e Filosofia da Ciência, Cracóvia, 1999. Tradução de Marcos Rodrigues da Silva, 2000.

SANTOS, W. L. P.; MORTIMER, E. F. Uma análise de pressupostos teóricos da abordagem C-T-S (Ciência- Tecnologia - Sociedade) no contexto da educação brasileira, Ensaio - Pesquisa em Educação em Ciências, v. 2, n. 2, p. 1 -23, dezembro, 2002.

SANTOS, B. S. Renovar a teoria crítica e reinventar a emancipação social, $1^{a}$ Edição, São Paulo: Boitempo, 2007.

SANTOS, B. S. Para Além do Pensamento Abissal: das linhas globais a uma ecologia de saberes In: SANTOS, B. S e MENESES, M. P. (Orgs.), Epistemologias do Sul. Coimbra: Edições Almedina, 2009.

SOUZA, J. Uma proposta de educação científica para a formação do docente do campo. Tese de Doutorado, Instituto de Física, UFRGS, 2020.

VENDRAMINI, C. R. Os desafios do MST e da educação na atualidade brasileira. Perspectiva, v. 31, n. 2, 2013. 